\title{
Preparation of polyaniline-modified local clay and study of its sorption capacity
}

\author{
Hadj Benhebal · Messaoud Chaib • Angélique Leonard • \\ Michel Crine $\cdot$ Stephanie D. Lambert
}

Received: 29 December 2013/Accepted: 11 March 2014/Published online: 17 April 2014

(C) The Author(s) 2014. This article is published with open access at Springerlink.com

\begin{abstract}
Clay minerals are frequently used in adsorption processes with aqueous solution; it was found that the adsorption properties of clays change when the samples are modified. In this context, polyaniline-modified clay nanocomposite (at $10 \%$ ) was prepared by in situ polymerization processes. The structural and morphological characteristics of the synthesized material are systematically examined by X-ray diffraction, scanning electron microscopy, thermo-gravimetry, differential scanning calorimetry and infrared spectroscopy techniques. The adsorption property of the modified clay was evaluated for the removal of a reactive dye (methylene blue) from aqueous solution at room temperature $\left(25^{\circ} \mathrm{C}\right)$ via batch adsorption.
\end{abstract}

Keywords Clays · Polyaniline $\cdot$ Adsorption $\cdot$ Methylene blue

\section{Introduction}

The widespread application of dyes in textiles, printing, dyeing, and food plants has produced a large amount of

H. Benhebal $(\bowtie) \cdot$ M. Chaib

Laboratoire de Chimie et Environnement, Université de Tiaret, BP 78 Zaaroura, 14000 Tiaret, Algeria

e-mail: benhebalh@yahoo.fr

A. Leonard · M. Crine $\cdot$ S. D. Lambert

Laboratoire de Génie chimique, B6a, Université de Liège,

4000 Liège, Belgium

S. D. Lambert

e-mail: stephanie.lambert@ulg.ac.be dye wastewater. Because some dyes and their degradation products may be carcinogens and toxic, the removal of dyes from wastewater becomes an important issue in the environmental protection [1]. Different techniques such as adsorption, oxidation, reduction, electrochemical and membrane filtration have been applied for the removal of these pollutants from the industrial effluents $[2,3]$. Adsorption techniques have proven successful in lowering dye concentration from industrial effluents by using adsorbents such as activated carbon, peat, chitin, clay, and others [4].

Natural Algerian clay minerals, e.g., kaolinite, smectite, illite, chlorite, etc., are very abundant materials with a low cost and porous texture. Due to their structural properties, high chemical stability, high specific surface area and high adsorption capacity, they can be used to remove dye from effluents. The clays can adsorb organic substances either on its external surfaces or within its interlamellar spaces, by interaction with or substitution of the exchange cations in those spaces [5].

One of the methods for obtaining absorbent clays with high adsorption capacity is their modification by polymers. Previous research demonstrated that the organic modifiers could change the surface property of the clays from hydrophilic to hydrophobic, and then significantly enhanced their affinity for organic contaminants [6]. Incorporation of guest electroactive polymers such as polyaniline (PANI), polypyrrole (PPy), etc., into host clay particles has attracted great attention because of their better processibility with colloidal stability, mechanical strength and novel electrical, catalytic properties [7].

In the present investigation an attempt has been made to prepare modified clay used as adsorbent for the removal of methylene blue from wastewater. 


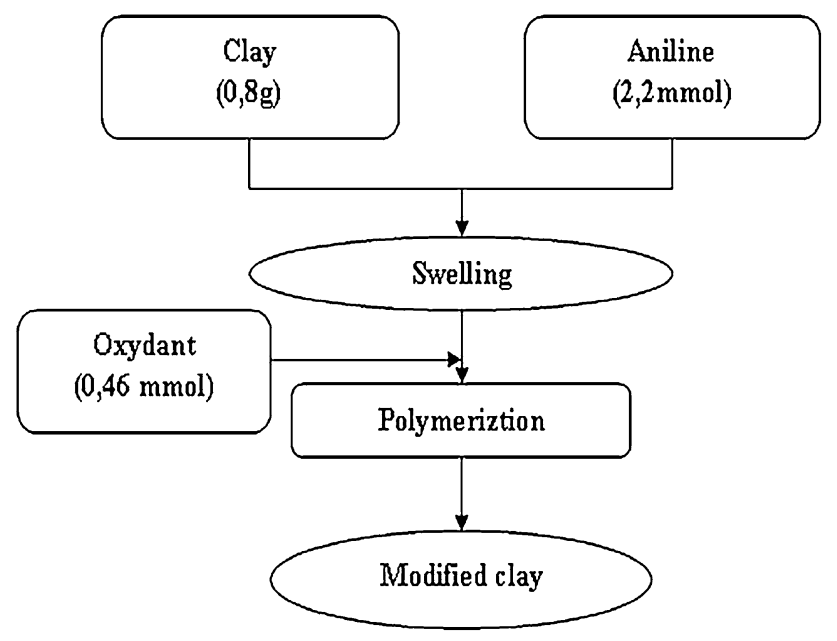

Fig. 1 Process for clay modification

\section{Experimental}

Materials

The raw clay was obtained locally from a deposit located $30 \mathrm{~km}$ from the town of Tiaret in western Algeria. The clay is of kaolinite/illite-type, having the following chemical composition: $\mathrm{SiO}_{2}(44.23 \%) ; \mathrm{Al}_{2} \mathrm{O}_{3}$ (10.75\%); $\mathrm{Fe}_{2} \mathrm{O}_{3}$ (4.31\%); $\mathrm{CaO}$ (16.58\%); $\mathrm{MgO}(2.68 \%) ; \mathrm{SO}_{3}(0.24 \%)$; $\mathrm{K}_{2} \mathrm{O}(1.75 \%) ; \mathrm{Na}_{2} \mathrm{O}(0.46 \%)$; PF (18.08\%).

All other reagents used in the experiments were of analytical grade and used directly as purchased: aniline $\left(\mathrm{C}_{6} \mathrm{H}_{7} \mathrm{~N}\right)$; oxidizing agent [ammonium persulfate $\left(\mathrm{NH}_{4}\right)_{2}$ $\mathrm{S}_{2} \mathrm{O}_{8}$ ]; sulfuric acid $\left(\mathrm{H}_{2} \mathrm{SO}_{4}\right)$.

\section{Modified clay preparation}

After recovery of the clay fraction by sedimentation, polyaniline-modified clay was prepared according the following procedure:

In a container of $50 \mathrm{~mL}, 0.46 \mathrm{mmol}$ of ammonium persulfate $\left(\mathrm{NH}_{4}\right)_{2} \mathrm{~S}_{2} \mathrm{O}_{8}$ as oxidant was dissolved into $50 \mathrm{~mL}$ of sulfuric acid $\mathrm{H}_{2} \mathrm{SO}_{4}$ solution $\left(0.5 \mathrm{~mol} \mathrm{~L}{ }^{-1}\right)$ already prepared.

In parallel in a flask, $2.2 \mathrm{mmol}$ of aniline $\left(\mathrm{C}_{6} \mathrm{H}_{7} \mathrm{~N}\right)$ was dissolved in $50 \mathrm{~mL}$ of solution of sulfuric acid $\mathrm{H}_{2} \mathrm{SO}_{4}$ and $0.8 \mathrm{~g}$ clay already prepared was added with aniline followed by stirring for $30 \mathrm{~min}$ to dissolve aniline. Then the two solutions were brought to the desired temperature (water bath).

The contents were poured into a bulb addition, after verifying that the temperature was correct (stirring was stopped to dip the thermometer, and the oxidizing solution was added drop by drop with the addition funnel over $30 \mathrm{~min}$, and then left while stirring approximately another $30 \min$ (Fig. 1).

\section{Characterization}

X-ray diffraction spectra have been measured by using a Philips PW 1830 goniometer using the $\mathrm{Cu}-\mathrm{K} \alpha$ line ( $\lambda=0.15458 \mathrm{~nm}$ ) radiation under $40 \mathrm{kV}$ and $100 \mathrm{~mA}$ and scanning with the $2 \theta$ ranging from $10^{\circ}$ to $70^{\circ}$. The crystal phases were identified by comparison with JCPDS cards.

Microstructures and morphologies were investigated using JEOL JSM-840 scanning electronic microscope (SEM) at an acceleration voltage of $20 \mathrm{kV}$. The samples were deposited onto carbon tape and coated with gold in a Balzers plasma sputterer (30 s at $30 \mathrm{~mA})$.

Thermo-gravimetry (TGA) and differential scanning calorimetry (DSC) were used in this work to study the behaviour of the modified clay with Netzsch DSC 204F1 Phoenix 240-12-0110-L instrument.

Infrared spectroscopy (IR) was used to identify the specific bands of the sample with a FTIR Perkin Elmer spectrophotometer.

\section{Results and discussion}

\section{Characterizations}

In Fig. 2 the XRD pattern of modified clay indicates the dominant association of kaolinite and illite minerals. The $2 \theta$ between $20^{\circ}$ and $30^{\circ}$ revealed the presence of kaolinite mineral [8]. Intercalation of PANI between the clay layers is evident from the two broad peaks and was observed centered at $2 \theta$ values $21^{\circ}$ and $25^{\circ}$, which are ascribed to the periodicity parallel and perpendicular to the polymer chain, respectively [9].

Figure 3 SEM image shows the surface morphology of prepared adsorbent with modified clay. The morphology of the kaolinite crystal is platelet shaped and the number of agglomerates has decreased relative to the analogous features in unmodified kaolinite [10, 11].

The TG and DSC curves shown in Fig. 4a, b represent the thermal degradation of modified clay. The TGA curve shows an initial weight loss up to $100{ }^{\circ} \mathrm{C}$, due to the loss of water or moisture from the polymer. The polymer is thermally stable up to $200{ }^{\circ} \mathrm{C}$; from 400 to $575^{\circ} \mathrm{C}$ organic material is removed from the sample. The endothermic peak at $547{ }^{\circ} \mathrm{C}$ represents the dehydroxylation of the kaolin sample forming metakaolin [12-14].

On the DSC curve, there are two endothermic peaks at around 75 and $275{ }^{\circ} \mathrm{C}$. The first one can be attributed to the expulsion adsorbed water and moisture from the sample and the second one is due to the thermal degradation of the material and the dehydroxylation of kaolinite.

The infrared absorption spectrum of sample (Fig. 5) possesses characteristic absorption bands. The broad 
Fig. 2 XRD pattern of raw material (a), pure polyaniline (b) and modified clay (c)
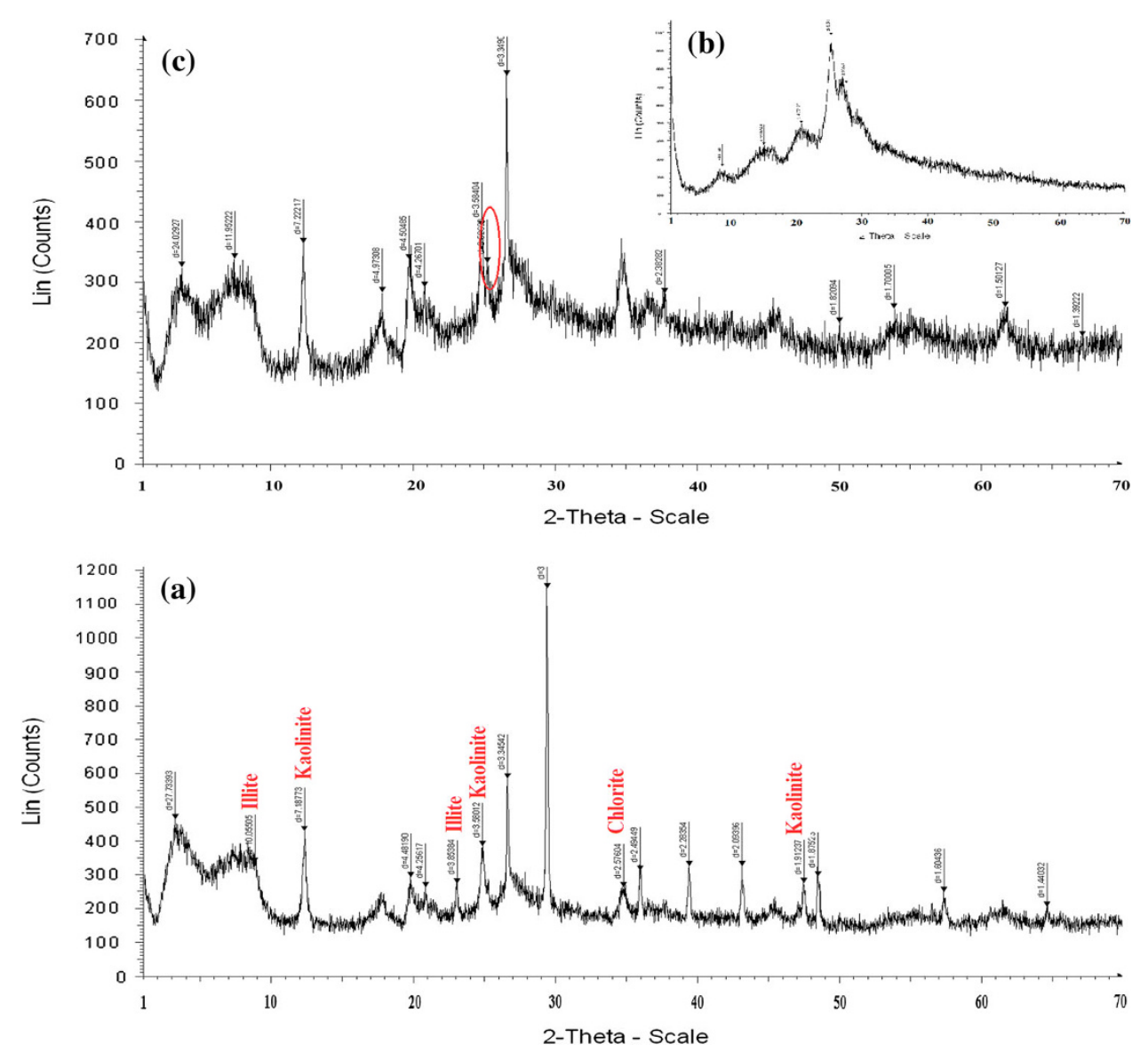

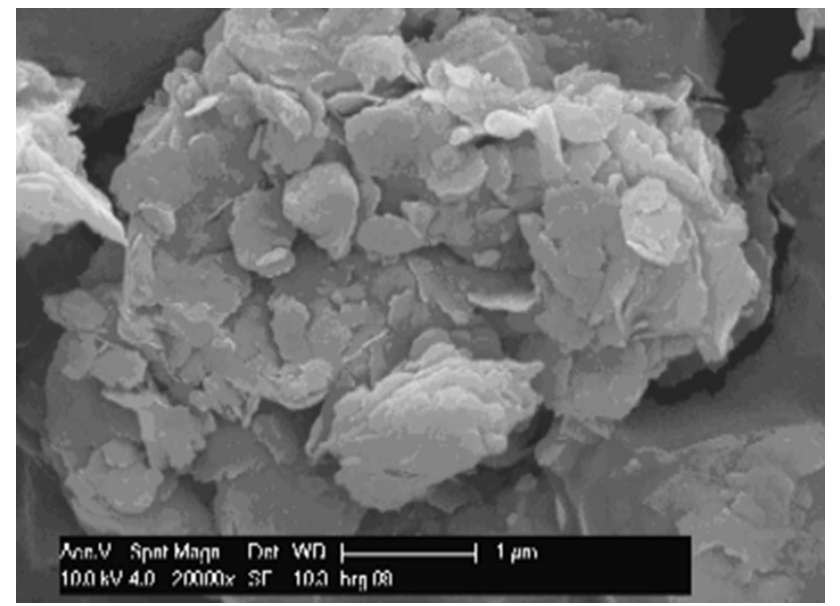

Fig. 3 SEM image of modified clay

infrared bands at $1,028 \mathrm{~cm}^{-1}[v(\mathrm{Si}-\mathrm{O})]$, assigned the clay minerals (kaolinite/illite) in the sample. The IR bands near $772,3,447 \mathrm{~cm}^{-1}$ also indicate the presence of kaolinite mineral. IR PANI showed characteristic bands at 1,543 and $1,426 \mathrm{~cm}^{-1}$ (stretching vibration of quinoid ring and benzenoid ring), $3,100 \mathrm{~cm}^{-1}$ (N-H str), $2,900 \mathrm{~cm}^{-1}$ (C-H str), and $1,291 \mathrm{~cm}^{-1}(\mathrm{C}-\mathrm{N})$ [15].
Adsorption experiment

\section{Equilibrium study}

The interest of this study is to determine the time required to reach the adsorption equilibrium of the dye; $0.1 \mathrm{~g}$ of adsorbent was added to $100 \mathrm{~mL}$ of dye solution of known concentration $\left(10 \mathrm{mg} \mathrm{L}^{-1}\right)$. The $\mathrm{pH}$ of solution was equal to 6 and at constant temperature $\left(25^{\circ} \mathrm{C}\right)$. The mixture was stirred on a rotary orbital shaker at $160 \mathrm{rpm}$.

The sample was withdrawn from the shaker at the predetermined time intervals (20 $\mathrm{min})$ and absorbents were separated from the solution by centrifugation at $4,000 \mathrm{rpm}$ for $15 \mathrm{~min}$. The absorbance of the supernatant solution was estimated to determine the residue of dye concentration $\left(C_{\mathrm{t}}\right)$.

In the Fig. 6 , is presented the amount of dye (MB) per gram of the adsorbent (polyaniline modified clay), $q_{\mathrm{e}}\left(\mathrm{mg} \mathrm{g}^{-1}\right)$ versus time.

$q_{\mathrm{e}}\left(\mathrm{mg} \mathrm{g}^{-1}\right)$ was calculated using:

$q_{e}=\left[\left(C_{0}-C_{e}\right) \times V\right] / w$

where $C_{0}$ and $C_{\mathrm{e}}$ are the initial and final MB concentrations ( $\mathrm{mg} \mathrm{L}^{-1}$ ) in the solution, respectively, $V$ is the volume of solution (L) and $w$ is the mass of adsorbent $(\mathrm{g})$. 
(a)

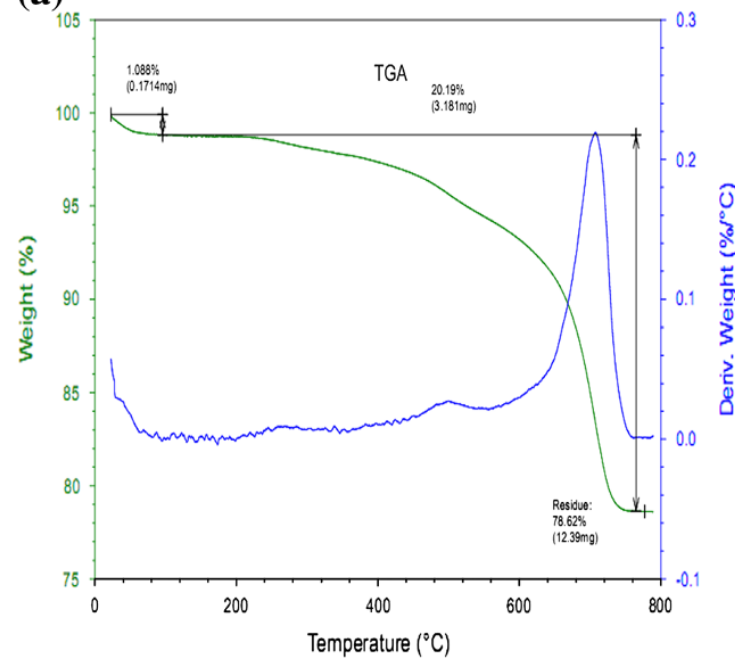

(b)

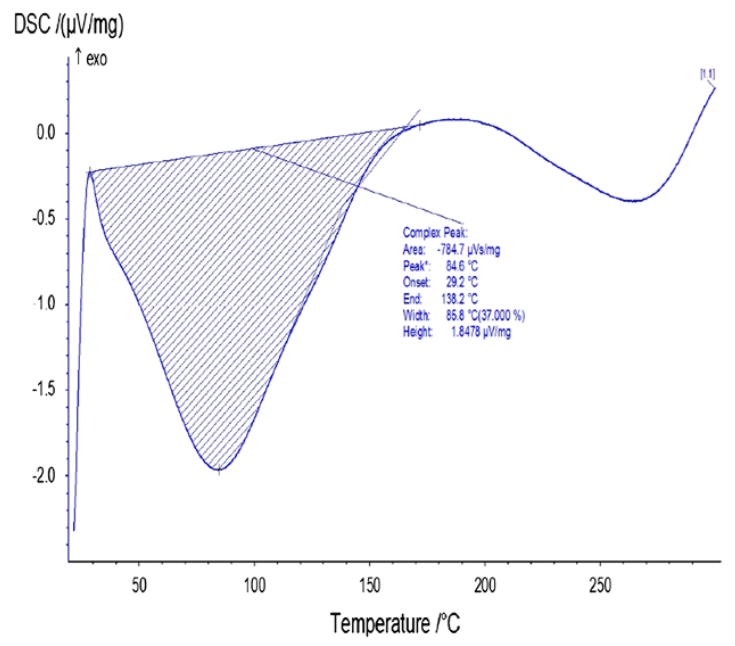

Fig. 4 a TG plot of modified clay. b Differential scanning calorimeter (DSC) thermogram of modified clay

Fig. 5 IR spectrum of modified clay

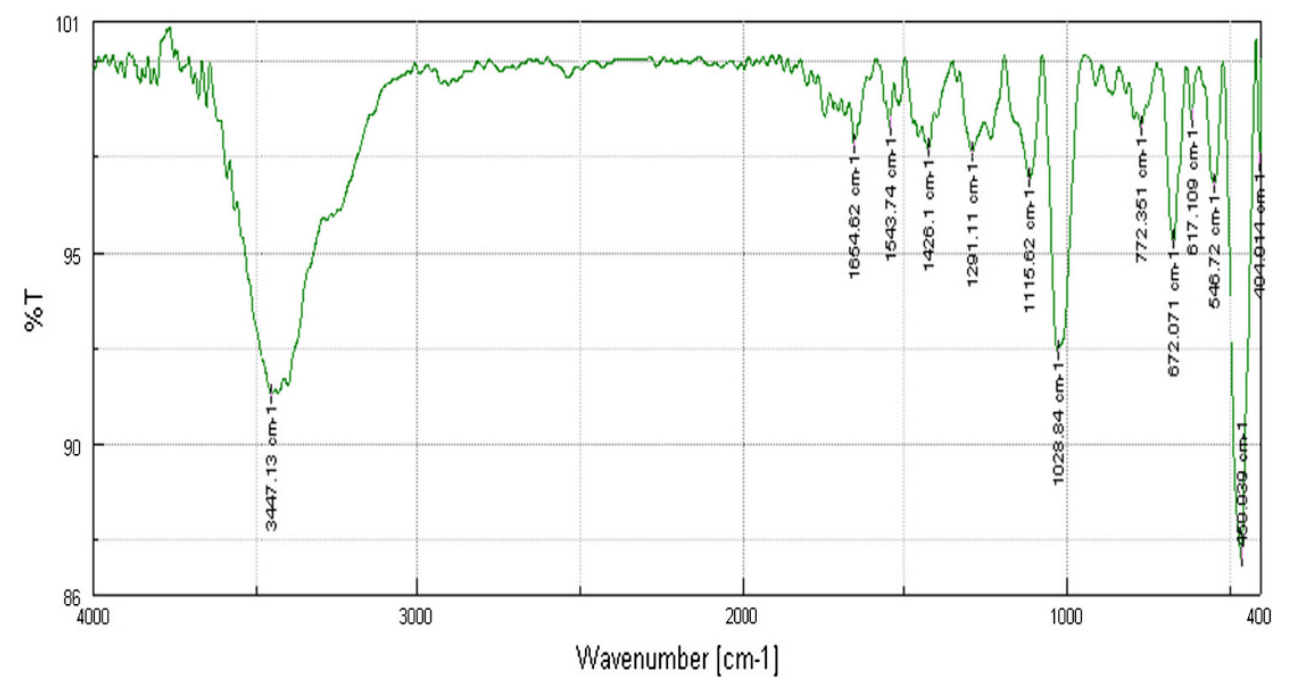

From the figure, adsorption is rapid for the first $20 \mathrm{~min}$ due to the adsorption of dye onto exterior surface, after that dye molecules enter into pores (interior surface), relatively slow process [16] and equilibrium is reached after $30 \mathrm{~min}$ which shows the effectiveness of the materials for the elimination of the dye.

\section{Effect of initial dye concentration}

A mass of $0.1 \mathrm{~g}$ of adsorbent was contacted with $100 \mathrm{~mL}$ solutions of dye concentrations $5,10,15$ and $20 \mathrm{mg} \mathrm{L}^{-1}$ at the $\mathrm{pH} 6$, at constant temperature $\left(25^{\circ} \mathrm{C}\right)$ and stirring at the speed of $400 \mathrm{rpm}$. Concentrations of $\mathrm{MB}$ were measured at equilibrium. The percentage of dye removal (Fig. 7) was determined using equation:

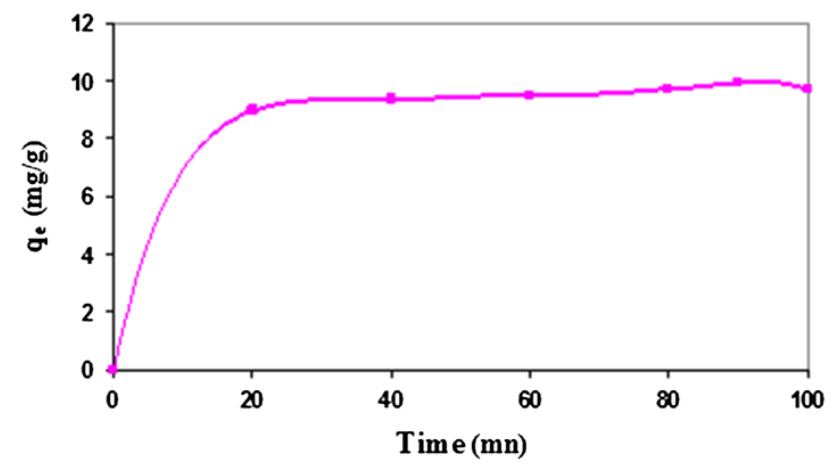

Fig. 6 Effect of contact time on the adsorption of $\mathrm{MB}$ dye $\left(T=25^{\circ} \mathrm{C}, \mathrm{pH}=6\right.$, dosage of adsorbent $=1.0 \mathrm{~g} \mathrm{~L}^{-1},[\mathrm{MB}]_{0}=$ $10 \mathrm{mg} \mathrm{L}^{-1}, V=100 \mathrm{~mL}$ ) 


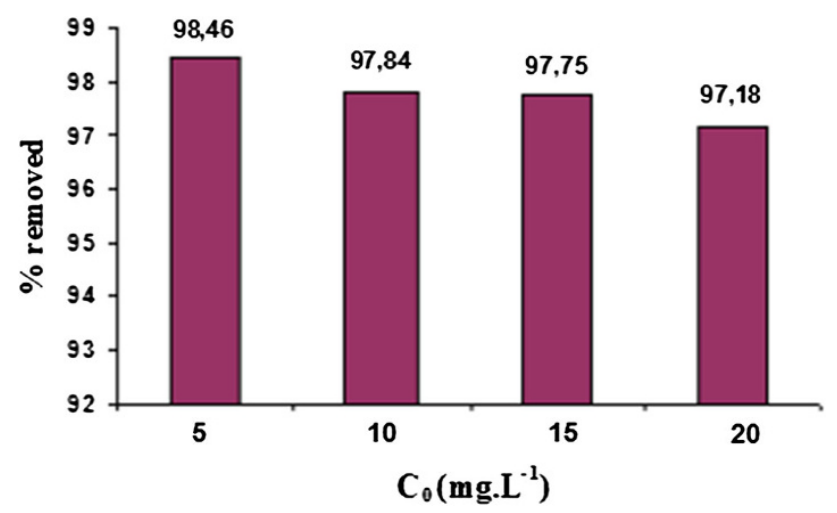

Fig. 7 Effect of initial concentration on the \% removal of $\mathrm{MB}$ $\left(T=25{ }^{\circ} \mathrm{C}, \quad \mathrm{pH}=6, \quad\right.$ dosage of adsorbent $=1.0 \mathrm{~g} \mathrm{~L}^{-1}, \quad V=$ $100 \mathrm{~mL}$ )

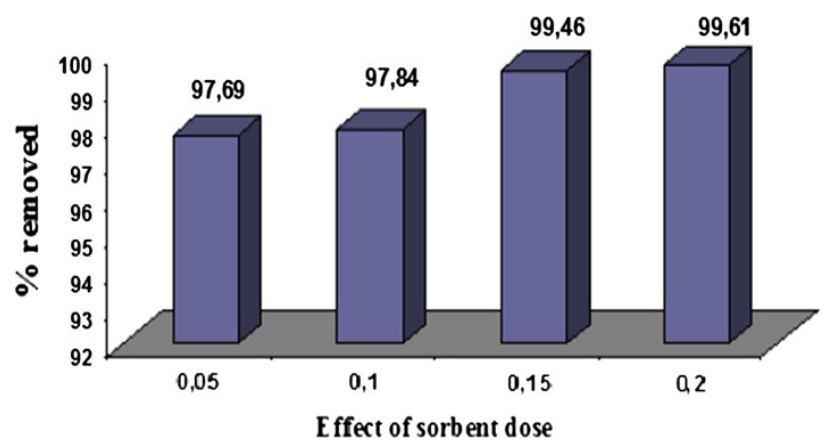

Fig. 8 Effect of adsorbent dosage on the \% removal of $\mathrm{MB}$ $\left(T=25^{\circ} \mathrm{C}, \mathrm{pH}=6,[\mathrm{MB}]_{0}=10 \mathrm{mg} \mathrm{L}^{-1}, V=100 \mathrm{~mL}\right)$

$\%$ Removed $=(C \mathrm{o}-C \mathrm{e}) \frac{100}{C \mathrm{o}}$

where, $C_{\mathrm{o}}$ and $C_{\mathrm{e}}$ are initial and equilibrium concentrations of dye $\left(\mathrm{mg} \mathrm{L}^{-1}\right)$, respectively.

At lower dye concentrations solute concentrations to the available surface area of adsorbent are higher, which cause an increase in color removal [17]. At higher concentrations, lower adsorption yield is due to the saturation of adsorption sites [17].

\section{Effect of adsorbent mass}

$0.05,0.1,0.15$ and $0.2 \mathrm{~g}$ of prepared sample (modified clay) was added to $100 \mathrm{~mL}$ dye solution. The initial dye concentration was $10 \mathrm{mg} \mathrm{L}^{-1}(\mathrm{pH} \mathrm{6)}$ at constant temperature $\left(25^{\circ} \mathrm{C}\right)$ and stirring at the speed of $400 \mathrm{rpm}$. Concentrations of $\mathrm{MB}$ were measured at equilibrium. The percentage of dye removal (Fig. 8) was determined using equation:

$\%$ Removed $=(C \mathrm{o}-C \mathrm{e}) \frac{100}{C \mathrm{o}}$

where, $C_{\mathrm{o}}$ and $C_{\mathrm{e}}$ are initial and equilibrium concentrations of dye $\left(\mathrm{mg} \mathrm{L}^{-1}\right)$, respectively.
It appears quite clear from Fig. 8 that the adsorption percentage removal increases with increase in adsorbent dose and reaches a maximum value of $99.61 \%$ at a dose of $0.2 \mathrm{~g}$ in $100 \mathrm{~mL}$ of solution.

\section{Conclusion}

In conclusion, the present work is a contribution to the enhancement of clay, an abundant and low-cost naturally occurring material for the preparation of adsorbent used in the treatment of wastewater and in particular the removal of dyes.

The adsorption of methylene blue onto polyanilinemodified clay from aqueous solutions was studied. Polyaniline-modified clay adsorbent was prepared by in situ polymerization processes and characterized by DRX, SEM, TGA, DSC and IR.

The adsorption of MB was highly dependent on various operating parameters such as contact time, initial dye concentrations and adsorbent dosage.

Open Access This article is distributed under the terms of the Creative Commons Attribution License which permits any use, distribution, and reproduction in any medium, provided the original author(s) and the source are credited.

\section{References}

1. Juang, L.-C., Wang, C.-C., Lee, C.-K., Hsu, T.-C.: Dyes adsorption onto organoclay and MCM-41. J. Environ. Eng. Manag. 17(1), 9-38 (2007)

2. Qin, J., Zhang, Q., Chuang, K.T.: Catalytic wet oxidation of p-chlorophenol over supported noble metal catalysts. Appl. Catal. B: Environ. 29, 115-123 (2001)

3. Fujitani, T., Nakamura, J.: The chemical modification seen in the $\mathrm{Cu} / \mathrm{ZnO}$ methanol synthesis catalysts. Appl. Catal. A: Gen. 191, 111-129 (2000)

4. Tahir, H.: Comparative trace metal contents in sediments and liquid waste from tanneries and the removal of chromium using zeolite-5A. Electron J Environ Agric Food Chem EJEAFCHE 4(4), 1021-1032 (2005)

5. Bouras, O., Chamj, T., Houari, H., Bollinger, J.C., Baudu, M.: Environ. Technol. 21, 405-411 (2002)

6. Jiang, J.-Q., Zeng, Z.: Comparison of modified montmorillonite adsorbents Part II: the effects of the type of raw clays and modification conditions on the adsorption performance. Chemosphere 53, 53-62 (2003)

7. Alexandre, M., Dubois, P.: Mater. Sci. Eng. 28, 1-63 (2000)

8. JCPDS: Selected powder diffraction data for minerals. In: Berry, L.G. (ed.) Joint Committee on powder diffraction standards. 1601 Park Lane, Swarthmore, Pennsylvania 19081, USA (1974)

9. Pouget, J.P., Jozefowicz, M.E., Epstein, A.J., Tang, X., MacDiarmid, A.G.: X-ray structure of polyaniline. Macromolecules 24(3), 779-789 (1991)

10. Mgbemena, C.O., Ibekwe, N.O., Sukumar, R., Menon, A.R.R.: Characterization of kaolin intercalates of oleochemicals derived from rubber seed (Hevea brasiliensis) and tea seed (Camellia sinensis) oils. J. King Saud Univ. Sci. 25, 149-155 (2013) 
11. Domka, L., Malicka, A., Stachowiak, N.: Production and structural investigation of polyethylene composites with modified kaolin. Acta Phys. Pol. A 114, 413-421 (2008)

12. Dohnalová, Ž., Svoboda, L., Šulcová, P.: J. Min. Metall. Sect. B 44, 63-69 (2008)

13. Ratheesh, R., Viswanathan, K.: Calorimetric and thermogravimetric studies in para toluene sulphonic acid (PTSA) doped polyaniline. Int. J. Sci. Res. 2(11), 466-468 (2013)

14. Heide, K., Földvari, M.: Thermochim. Acta 446, 106-113 (2006)

15. Sudha, J.D., Sivakala, S., Chandrakanth, C.K., Neethu, K.S., Rohini, K.N., Ramakrishnan, R.: Percolated conductive polyaniline-clay nanocomposite in polyvinyl chloride through the combined approach porous template and self-assembly. Express Polym. Lett. 8(2), 107-115 (2014)

16. Ahmad, R., Kumar, R.: Adsorption studies of hazardous Malachite Green onto treated ginger waste. J. Environ. Manag. 91(4), 1032-1038 (2010)

17. Ozer, A., Akkaya, G., Turabik, M.: The biosorption of Acid Red 337 and Acid Blue 324 on Enteromorpha prolifera: the application of nonlinear regression analysis to dye biosorption. Chem. Eng. J. 112, 181-190 (2005) 